\title{
Analytic models of high-temperature hohlraums
}

\author{
W. A. Stygar, R. E. Olson, R. B. Spielman, and R. J. Leeper \\ Sandia National Laboratories, MS 1194, Albuquerque, New Mexico 87185-1194 \\ (Received ? November 2000)
}

\begin{abstract}
A unified set of high-temperature-hohlraum models has been developed. For a simple hohlraum, $P_{S}=\left[A_{S}+\left(1-\alpha_{W}\right) A_{W}+A_{H}\right] \sigma T_{R}{ }^{4}+(4 V \sigma / c)\left(d T_{R}{ }^{4} / d t\right)$ where $P_{S}$ is the total power radiated by the source, $A_{S}$ is the source area, $A_{W}$ is the area of the cavity wall excluding the source and holes in the wall, $A_{H}$ is the area of the holes, $\sigma$ is the Stefan-Boltzmann constant, $T_{R}$ is the radiation brightness temperature, $V$ is the hohlraum volume, and $\mathrm{c}$ is the speed of light. The wall albedo $\alpha_{\mathrm{w}} \equiv\left(\mathrm{T}_{\mathrm{w}} / \mathrm{T}_{\mathrm{R}}\right)^{4}$ where $T_{W}$ is the brightness temperature of area $A_{W}$. The net power radiated by the source $P_{N}=P_{S}-A_{s} \sigma T_{R}{ }^{4}$, which suggests that for laser-driven hohlraums the conversion efficiency $\eta_{C E}$ be defined as $P_{N} / P_{\text {LASER }}$. The characteristic time required to change $T_{R}{ }^{4}$ in response to a change in $P_{N}$ is $4 V / c\left[\left(1-\alpha_{W}\right) A_{W}+A_{H}\right]$. Using this model, $T_{R}, \alpha_{W}$, and $\eta_{C E}$ can be expressed in terms of quantities directly measurable in a hohlraum experiment. For a steady-state hohlraum that encloses a convex capsule, $P_{N}=\left\{\left(1-\alpha_{W}\right) A_{W}+A_{H}+\left[\left(1-\alpha_{C}\right)\left(A_{S}+A_{W} \alpha_{W}\right) A_{C} / A_{T}\right]\right\} \sigma T_{R C}{ }^{4}$ where $\alpha_{C}$ is the capsule albedo, $A_{C}$ is the capsule area, $A_{T} \equiv\left(A_{S}+A_{W}+A_{H}\right)$, and $T_{R C}$ is the brightness temperature of the radiation that drives the capsule. According to this relation, the capsule-coupling efficiency of the baseline National-Ignition-Facility (NIF) hohlraum is $15 \%$ higher than predicted by previous analytic expressions. A model of a hohlraum that encloses a $\mathrm{z}$ pinch is also presented.
\end{abstract}

\section{INTRODUCTION}

High-temperature hohlraums are being used for indirect-drive inertial-confinement-fusion (ICF), high-energy-density, equation-of-state, and astrophysics research [1-82]. Laserdriven-hohlraum experiments have been conducted at $100-300 \mathrm{eV}[2,4,5-12,14-22,24$ $26,38,43,48,51,52,71,74,77]$. National Ignition Facility (NIF) hohlraums will be driven by $400 \mathrm{TW}$ of laser power, and are expected to reach $300 \mathrm{eV}$ in systems designed to achieve thermonuclear ignition $[28,33,35,40,50,51,63,80]$. Temperatures of $60-180 \mathrm{eV}$ have been produced in z-pinch-driven cavities 
$[15,41,43,45,53,61,64,65,69,73,76,78,79,81]$. A 60-MA z-pinch driver would achieve $210-300 \mathrm{eV}[62,64,66]$. Megajoule heavy-ion beams focused to spots a few millimeters in diameter would drive hohlraums to $200-300 \mathrm{eV}[13,23,32,49,51,54-58,75]$.

Radiation-hydrodynamic simulations must be performed to characterize high-temperature hohlraums accurately. Nevertheless, it is convenient to obtain analytic estimates of hohlraum temperatures, both for existing systems and configurations proposed for future facilities. Useful steady-state power-balance models (sometimes expressed in terms of energy) have been developed and are commonly used for zero-dimensional calculations $[1,6,8-10,12-14,19,24,29,35,36,51,62,67,76]$.

In Section II we develop a time-dependent model and quantify the error introduced by the steady-state approximation. The model does not assume the source area is negligible, and distinguishes between the radiation, wall, and source brightness temperatures. For a laser-driven hohlraum the model leads to a definition of laser-conversion efficiency in terms of the net source power. In Section III we use the model to express the radiation brightness temperature, wall albedo, and (for a laser-driven system) laser-conversion efficiency in terms of directly-measurable quantities. (The measurements can, for example, be made with a power-imaging diagnostic as described by Olson et. al. [83].) We also show how, in certain situations, the radiation temperature can be obtained from a single x-ray-power measurement, as described by Decker and coworkers [38]. In Section IV, following ideas developed by Murakami and Meyer-ter-Vehn [13], we generalize the model to include a convex inertial-confinement-fusion capsule. The expressions obtained for the brightness temperature of the radiation that drives the capsule, and the capsulecoupling efficiency, take into account the anisotropic radiation flux and source and hole areas self-consistently. In Section $\mathrm{V}$ we model a cavity that encloses a centrally-located convex source, such as a $\mathrm{z}$ pinch. The models in these Sections describe single cavities, and can be applied to a system of connected cavities as described by Tsarkis et. al. [10], Rosen [19,35], Hammer et. al. [62], and Cuneo et. al. [76].

The models outlined in Sections II, IV, and V must be supplemented with additional information to determine the wall albedo, source power, and radiation temperatures. Analytic expressions for the albedo have been developed by Rosen $[1,29,35,51,84]$ and Pakula, Sigel et. al $[3,6,9,14,18,84,85]$. The source power might best be obtained from measurements or numerical simulations. For a z-pinch-driven hohlraum, we can estimate the source power from measurements in a partially-open geometry, as described in Section VI. In Section VII we comment briefly on NIF and Z-accelerator hohlraum designs. 


\section{DISCLAIMER}

This report was prepared as an account of work sponsored by an agency of the United States Government. Neither the United States Government nor any agency thereof, nor any of their employees, make any warranty, express or implied, or assumes any legal liability or responsibility for the accuracy, completeness, or usefulness of any information, apparatus, product, or process disclosed, or represents that its use would not infringe privately owned rights. Reference herein to any specific commercial product, process, or service by trade name, trademark, manufacturer, or otherwise does not necessarily constitute or imply its endorsement, recommendation, or favoring by the United States Government or any agency thereof. The views and opinions of authors expressed herein do not necessarily state or reflect those of the United States Government or any agency thereof. 


\section{DISCLAIMER}

Portions of this document may be illegible in electronic image products. Images are produced from the best available original document. 


\section{SIMPLE HOHLRAUM}

We first consider an idealized radiation cavity with volume $\mathrm{V}$ driven by an $\mathrm{x}$-ray source. We assume the total area $A_{T}$ of the surface that encloses $V$ is equal to $A_{S}+A_{H}+A_{W}$, where $A_{S}$ is the source area, $A_{H}$ is the area of holes in the hohlraum wall, and $A_{W}$ is the area of the wall excluding the source and holes. This is valid when the source region can be characterized by an area $A_{S}$ that is part of $A_{T}$, and does not apply, for example, when a significant fraction of the source $x$ rays are emitted by a plasma that fills $V$. When the source is not located inside the hohlraum, $A_{s}$ is the area of the aperture through which the source radiation enters. $A_{H}$ includes the area of diagnostic apertures in the hohlraum wall, and for a laser-driven hohlraum, the laser entrance holes.

We assume areas $A_{S}$ and $A_{H}$ are uniformly distributed across $A_{T}$, radiation entering the cavity from areas $A_{S}$ and $A_{W}$ is Lambertian, and no radiation enters the cavity through $A_{H}$. We define $U_{R}$ to be the energy in radiation that fills $V$ and assume the radiation is homogeneous and isotropic. Under these conditions the radiation flux incident on $A_{T}$ is equal to $\left(\mathrm{cU}_{\mathrm{R}} / 4 \mathrm{~V}\right)$, independent of the spectrum, where $\mathrm{c}$ is the speed of light [86]. Hence the radiation brightness temperature $T_{R}$ is given by

$$
\sigma T_{\mathrm{R}}^{4}=\frac{c U_{\mathrm{R}}}{4 \mathrm{~V}}
$$

where $\sigma$ is the Stefan-Boltzmann constant. (Equations are in MKS units throughout.)

Equating $\mathrm{dU}_{\mathrm{R}} / \mathrm{dt}$ to the difference between the incoming and outgoing power at the surface defined by $\mathrm{A}_{\mathrm{T}}$ gives

$$
\frac{d U_{R}}{d t}=\left(P_{S}+P_{W}\right)-\left(A_{S}+A_{W}+A_{H}\right) \sigma T_{R}^{4}
$$

where $P_{S}$ is the total power entering the cavity from area $A_{s}$, and $P_{w}$ is the total power entering the cavity from area $A_{w}$. (No assumptions have been made, of course, about the absorptivities of areas $A_{s}$ and $A_{w}$.) Eq. 2 assumes that either the hohlraum is evacuated, or if it is filled with plasma, that the power required to heat the plasma is much less than $\mathrm{dU}_{\mathrm{R}} / \mathrm{dt}$. The above equation also assumes PdV work due to motion of the cavity wall can 
be neglected. The brightness temperatures $T_{s}$ and $T_{w}$ of areas $A_{s}$ and $A_{w}$, respectively, are obtained from

$$
\sigma T_{\mathrm{S}}^{4}=\frac{\mathrm{P}_{\mathrm{S}}}{\mathrm{A}_{\mathrm{S}}} \quad \text { and } \quad \sigma T_{\mathrm{w}}^{4}=\frac{\mathrm{P}_{\mathrm{w}}}{\mathrm{A}_{\mathrm{w}}}
$$

Eqs. 1-3 can be re-written as:

$$
P_{S}=\left[A_{S}+\left(1-\alpha_{W}\right) A_{W}+A_{H}\right] \sigma T_{R}^{4}+\frac{4 V \sigma}{c} \frac{d T_{R}^{4}}{d t}
$$

where $\alpha_{\mathrm{w}}$, the wall albedo, is defined by:

$$
\alpha_{W} \equiv \frac{P_{W}}{A_{w} \sigma T_{R}^{4}}=\left(\frac{T_{W}}{T_{R}}\right)^{4} .
$$

$P_{w}$ is the sum of the incident hohlraum-radiation power reflected from the area $A_{W}$ and the power reemitted. For most experiments of interest, little of the radiation incident on $A_{w}$ is reflected. In this limit the albedo is due only to reemission, and might more correctly be referred to as the reemission coefficient [6].

Over time periods when $\left[A_{S}+\left(1-\alpha_{W}\right) A_{W}+A_{H}\right]$ does not change significantly, we can define a hohlraum time constant $\tau_{H}$ as the characteristic time required to change $T_{R}{ }^{4}$ in response to a change in $P_{s}$ :

$$
\tau_{H} \equiv \frac{4 V}{c\left[A_{S}+\left(1-\alpha_{W}\right) A_{W}+A_{H}\right]}
$$

We note $\tau_{H}$ increases as the hohlraum becomes more efficient, i.e., as $\left[\left(1-\alpha_{W}\right) A_{W}+A_{H}\right] \rightarrow$ 0 .

Eq. 6 is valid for volumes with arbitrary shape, and takes into account the source and hole areas. The time constant implicit in Eq. 4.20 of Ref. 8 is $-4 R / 3 c\left(\ln \alpha_{w}\right)$, where it is assumed the cavity is spherical, the cavity radius $=R$, and the source and hole areas can be neglected. Eq. 6 reduces to this expression when $V=4 \pi R^{3} / 3, A_{W}=4 \pi R^{2}, A_{s}=A_{H}=0$, and $0<\left(1-\alpha_{\mathrm{w}}\right) \ll 1$. 
Since the hohlraum-radiation power incident on $A_{S}$ is $A_{S} \sigma T_{R}{ }^{4}$, the net power entering the cavity through $\mathrm{A}_{\mathrm{S}}$ is

$$
P_{N}=P_{S}-A_{S} \sigma T_{R}^{4}
$$

Combining Eqs. 4 and 7 gives:

$$
P_{N}=\left[\left(1-\alpha_{W}\right) A_{W}+A_{H}\right] \sigma T_{R}^{4}+\frac{4 V \sigma}{c} \frac{d T_{R}^{4}}{d t}
$$

The characteristic time required to change $\mathrm{T}_{\mathrm{R}}^{4}$ in response to a change in $\mathrm{P}_{\mathrm{N}}$ is:

$$
\tau_{H N} \equiv \frac{4 V}{c\left[\left(1-\alpha_{W}\right) A_{W}+A_{H}\right]} \text {. }
$$

In the steady state (when $\mathrm{dU}_{\mathrm{R}} / \mathrm{dt}=0$ ) Eqs. 7 and 8 become:

$$
P_{S}-A_{S} \sigma T_{R}^{4}=P_{N}=\left[\left(1-\alpha_{W}\right) A_{W}+A_{H}\right] \sigma T_{R}^{4} .
$$

This relation suggests that if $A_{T}$ and $A_{H}$ are held constant and $P_{N}$ is independent of $A_{S}$, then $T_{R}$ is maximized when $A_{S}=A_{T}-A_{H}$ and $A_{W}=0$. If $P_{N}$ is not independent of $A_{S}$, there may be a different value of $A_{S}$ that maximizes $T_{R}$. We note also that as $\left[\left(1-\alpha_{w}\right) A_{W}+A_{H}\right] \rightarrow 0$, i.e., as the hohlraum becomes increasingly efficient, $T_{R} \rightarrow T_{S}$, the brightness temperature of the source.

Eq. 10 is similar, but not identical, to previous expressions of the steady-state power balance for a zero-dimensional hohlraum. Some of the earlier discussions define $A_{W}$ to include the source area, which is equivalent to assuming $A_{S}=0$. In some discussions the source term is a net power not defined as in Eq. 10; in others, it is not clear whether the net or total source power is intended. Some discussions use $T_{R}$ and $T_{W}$ interchangeably. However, for most situations of current interest Eq. 10 is consistent to first order with previous expressions.

For a laser-driven hohlraum the source term commonly used is $\eta_{C E} P_{\text {LASER }}$, where $\eta_{C E}$ is the instantaneous conversion efficiency from laser to $\mathrm{x}$-ray power. We propose $\eta_{\mathrm{CE}}$ be defined as 


$$
\eta_{\mathrm{CE}} \equiv \frac{P_{\mathrm{N}}}{\mathrm{P}_{\text {LASER }}}=\frac{\mathrm{P}_{\mathrm{S}}-\mathrm{A}_{\mathrm{S}} \sigma \mathrm{T}_{\mathrm{R}}^{4}}{\mathrm{P}_{\text {LASER }}}
$$

which is the conversion efficiency of laser light to x-ray-source power that exceeds the hohlraum-radiation power incident on the source. In an open geometry $\eta_{C E}=P_{N} / P_{L A S E R}=$ $\mathrm{P}_{\mathrm{S}} / \mathrm{P}_{\text {LASER }}$.

Since Eq. 10 is more convenient than Eq. 4, it is useful to estimate the error due to the assumption $\mathrm{dU}_{\mathrm{R}} / \mathrm{dt}$ can be neglected. We define $(1-\delta)$ to be the ratio of $\mathrm{T}_{\mathrm{R}}{ }^{4}$ as determined by Eq. 4 , to $T_{R}{ }^{4}$ as determined by Eq. 10 , where $\delta$ is the fractional error. When $P_{S}$ and $\left[A_{S}+\left(1-\alpha_{W}\right) A_{W}+A_{H}\right]$ are constant we estimate from Eq. 4:

$$
T_{R}^{4}=\frac{P_{S}}{\sigma\left[A_{S}+\left(1-\alpha_{W}\right) A_{W}+A_{H}\right]}\left[1-\exp \left(-\frac{t}{\tau_{H}}\right)\right]
$$

assuming $\mathrm{T}_{\mathrm{R}}{ }^{4}=0$ at $\mathrm{t}=0$. From Eqs. 10 and 12 we obtain:

$$
\delta=\exp \left(-\frac{t}{\tau_{H}}\right)
$$

which equals $5 \%$ when $\mathrm{t} \approx 3 \tau_{\mathrm{H}}$.

When $P_{S} \propto t^{4 n}$ where $4 n$ is a positive integer (i.e., the source temperature is approximately proportional to $\left.t^{n}\right),\left[A_{S}+\left(1-\alpha_{W}\right) A_{W}+A_{H}\right)$ is constant, and $t<<\tau_{H}$, we find from Eq. 4 :

$$
\mathrm{T}_{\mathrm{R}}^{4} \approx \frac{\mathrm{P}_{\mathrm{S}}}{\sigma\left[\mathrm{A}_{\mathrm{S}}+\left(1-\alpha_{\mathrm{W}}\right) \mathrm{A}_{\mathrm{W}}+\mathrm{A}_{\mathrm{H}}\right]}\left[\frac{\mathrm{t}}{(4 \mathrm{n}+1) \tau_{\mathrm{H}}}\right]
$$

assuming $\mathrm{T}_{\mathrm{R}}{ }^{4}=0$ at $\mathrm{t}=0$. From Eqs. 10 and 14 we obtain:

$$
\delta \approx 1-\left[\frac{t}{(4 n+1) \tau_{H}}\right]
$$

When $\mathrm{t} \gg 4 \mathrm{n} \tau_{\mathrm{H}}$ : 


$$
\begin{gathered}
T_{R}^{4} \approx \frac{P_{S}}{\sigma\left[A_{S}+\left(1-\alpha_{W}\right) A_{W}+A_{H}\right]}\left[1-\left(\frac{4 n}{t / \tau_{H}}\right)\right] \\
\delta \approx \frac{4 n}{t / \tau_{H}}
\end{gathered}
$$

When $\mathrm{P}_{\mathrm{S}} \propto \mathrm{t}^{4}$ (and $\mathrm{T}_{\mathrm{R}}$ is approximately proportional to $\mathrm{t}$ ), $\delta=5 \%$ when $\mathrm{t} \approx 80 \tau_{\mathrm{H}}$.

Eqs. 12-17 are expressed in terms of $P_{S}$ and $\tau_{H}$; similar expressions can be readily obtained in terms of $\mathrm{P}_{\mathrm{N}}$ and $\tau_{\mathrm{HN}}$.

\section{III. $T_{R}, \alpha_{\mathrm{w}}$, AND $\eta_{\mathrm{CE}}$ IN TERMS OF DIRECTLY-MEASURABLE QUANTITIES}

The results of the previous Section can be used to suggest methods for making timeresolved measurements of $T_{R}, \alpha_{W}$, and $\eta_{C E}$ inside a hohlraum. Combining Eqs. 1 and 2 we find

$$
A_{T} \sigma\left[T_{T}^{4}-T_{R}^{4}\right]=\frac{4 V \sigma}{c} \frac{d T_{R}^{4}}{d t}=\frac{d U_{R}}{d t}
$$

where $T_{T} \equiv\left(\left(P_{S}+P_{W}\right) / A_{T} \sigma\right)^{1 / 4}$ is the brightness temperature of the total wall area $A_{T}$. Hence $\mathrm{dU}_{\mathrm{R}} / \mathrm{dt}$ is equal to the difference between $\mathrm{A}_{T} \sigma \mathrm{T}_{\mathrm{T}}{ }^{4}$ (the total power emitted by $A_{T}$ ) and $A_{T} \sigma T_{R}^{4}$ (the total power incident on $A_{T}$ ).

When $t>\left(4 V / A_{T} c\right)\left(i . e .\right.$, when $\left.d U_{R} / d t \approx 0\right)$ Eqs. 3 and 18 can be combined to give:

$$
\sigma \mathrm{T}_{\mathrm{R}}^{4}=\sigma \mathrm{T}_{\mathrm{T}}^{4}=\mathrm{f}_{\mathrm{S}} \sigma \mathrm{T}_{\mathrm{S}}^{4}+\mathrm{f}_{\mathrm{W}} \sigma \mathrm{T}_{\mathrm{W}}^{4}
$$

where $f_{S} \equiv\left(A_{S} / A_{T}\right)$ and $f_{W} \equiv\left(A_{w} / A_{T}\right)$. In the steady state, the radiation brightness temperature equals the brightness temperature of $A_{T}$, and $T_{R}{ }^{4}$ is a linear combination of $\mathrm{T}_{\mathrm{S}}{ }^{4}$ and $\mathrm{T}_{\mathrm{w}}{ }^{4}$. Eqs. 10 and 19 are equivalent; however, Eq. 19 gives $\mathrm{T}_{\mathrm{R}}(\mathrm{t})$ as a function of $f_{S}, f_{w}, T_{s}$, and $T_{w}$, quantities that can be directly measured as a function of time in a hohlraum experiment $[83,87-106]$.

Results by Decker et. al. [38] and Eq. 19 suggest that a single measurement can be used to obtain $T_{R}(t)$. As described in [38], we consider an $x$-ray-flux diagnostic that views the 
hohlraum wall, with part of the source and no holes in the field of view. We define $v_{s}$ to be the fraction of the detector's field of view occupied by the source, and $v_{W} \equiv 1-v_{s}$. If the diagnostic is designed such that $v_{S}=\left[A_{S} /\left(A_{s}+A_{W}\right)\right]$ and $v_{w}=\left[A_{w} /\left(A_{s}+A_{W}\right)\right]$, we have from Eq. 19:

$$
\sigma T_{R}^{4}=\frac{A_{S}+A_{W}}{A_{T}}\left[v_{S} \sigma T_{S}^{4}+v_{W} \sigma T_{W}^{4}\right]=\left(f_{S}+f_{W}\right)\left(\frac{P_{\text {VIEW }}}{A_{\text {VIEW }}}\right)
$$

where $P_{\text {VIEW }} \equiv A_{\text {VIEW }}\left(v_{S} \sigma T_{S}{ }^{4}+v_{W} \sigma T_{W}{ }^{4}\right)$ is the total power emitted by the field of view and $\mathrm{A}_{\mathrm{VIEW}}$ is its area. In such an arrangement the measured flux $\left(\mathrm{P}_{\mathrm{VIEW}} / \mathrm{A}_{\mathrm{VIEW}}\right)$ would be directly proportional to $T_{R}{ }^{4}$. Using this technique to measure $T_{R}(t)$ is, of course, meaningful only if $f_{s}$ and $f_{w}$ do not change significantly during the period of interest.

Combining Eqs. 5 and 19 gives the wall albedo:

$$
\alpha_{W}=\frac{1}{\left(\frac{A_{S}}{A_{T}}\right)\left(\frac{T_{S}}{T_{W}}\right)^{4}+\left(\frac{A_{W}}{A_{T}}\right)}=\frac{1}{f_{S}\left(\frac{T_{S}}{T_{W}}\right)^{4}+f_{w}} .
$$

Hence $\alpha_{\mathrm{w}}(\mathrm{t})$ can be obtained inside a hohlraum from time-resolved measurements of $\mathrm{f}_{\mathrm{S}}$, $f_{w}$, and $\left(T_{S} / T_{w}\right)^{4}$. These quantities might be obtained, for example, with an $x$-ray-framing camera [93]. It has been proposed [34,46,75,80] that optimized wall-material mixtures be used to increase albedos; Eq. 21 suggests one technique for testing such mixtures inside a hohlraum.

Since Eq. 21 implicitly assumes the net power is as defined by Eq. 7, and distinguishes between the wall and radiation temperatures, it differs from a similar expression for the albedo given as Eq. 8.4 in Ref. 51:

$$
\alpha_{w}=\frac{1}{\left(\frac{A_{S}}{A_{w}}\right)\left(\frac{T_{S}}{T_{w}}\right)^{4}+\left(\frac{A_{W}-A_{S}-A_{H}}{A_{w}}\right)} \text {. }
$$

However Eqs. 21 and 22 are approximately equivalent when $A_{\mathrm{W}} \approx A_{T}$.

For a laser-driven hohlraum, combining Eqs. 11 and 19 gives the conversion efficiency: 


$$
\eta_{\text {CE }}=\frac{A_{S}}{P_{\text {LASER }}}\left[\left(1-f_{S}\right) \sigma T_{S}^{4}-f_{W} \sigma T_{W}^{4}\right]
$$

Consequently we can determine $\eta_{\mathrm{CE}}(\mathrm{t})$ inside a hohlraum from time-resolved measurements of $f_{s}, f_{w}, T_{s}{ }^{4}$, and $T_{w}{ }^{4}$.

The quantities $\mathrm{f}_{\mathrm{s}}, \mathrm{f}_{\mathrm{w}}, \mathrm{T}_{\mathrm{s}}{ }^{4}, \mathrm{~T}_{\mathrm{w}}{ }^{4}$, and $\left(\mathrm{T}_{\mathrm{s}} / \mathrm{T}_{\mathrm{w}}\right)^{4}$ might be obtained from an $\mathrm{x}$-ray framing camera [93] and a filtered array of $x$-ray detectors, as described in [64,83]. According to Eqs. 19, 21, and 23, such a system could in principle provide $T_{R}(t), \alpha_{E}(t)$, and $\eta_{C E}(t)$ using a single aperture in the hohlraum wall. When $f_{S}$ and $f_{w}$ are relatively constant during the time of interest, only measurements of $\mathrm{T}_{\mathrm{S}}{ }^{4}$ and $\mathrm{T}_{\mathrm{w}}{ }^{4}$ would be required.

\section{HOHLRAUM WITH A CONVEX CAPSULE}

\section{A. Two radiation temperatures}

\section{The source directly irradiates the capsule}

We now assume the hohlraum described in Sections II and III encloses a centrallylocated convex capsule, such as might be used in ICF experiments. Since a convex surface cannot irradiate itself, the radiation flux incident on the capsule is, in general, not the same as the flux incident on the rest of the cavity wall [13]. We also assume the source is allowed to irradiate the capsule directly, and is not blocked by shields to improve radiation symmetry. This applies, for example, to proposed NIF ignition hohlraums $[28,33,35,40,47,50,51,63,80]$, distributed-radiator heavy-ion-beam-driven hohlraums [56-58,75], and the central cavity in the z-pinch-driven system proposed by Hammer et. al $[62,64,76,81]$.

As in Sections II and III, we assume the area of the outer hohlraum wall $A_{T}$ equals $\left(A_{S}+A_{W}+A_{H}\right)$, areas $A_{S}$ and $A_{H}$ are uniformly distributed across $A_{T}$, and radiation entering the cavity from areas $A_{S}$ and $A_{W}$ is Lambertian. We define $\sigma T_{R}{ }^{4}$ to be the radiation flux incident on $A_{T}$, and $\sigma T_{R C}{ }^{4}$ to be the flux incident on the capsule area $A_{C}$. We assume $\sigma \mathrm{T}_{\mathrm{R}}{ }^{4}$ and $\sigma \mathrm{T}_{\mathrm{RC}}{ }^{4}$ are uniform on areas $\mathrm{A}_{\mathrm{T}}$ and $\mathrm{A}_{\mathrm{C}}$, respectively.

Under these conditions Eq. 4 becomes (neglecting $\mathrm{dU}_{\mathrm{R}} / \mathrm{dt}$ ): 


$$
P_{S}=\left[A_{S}+\left(1-\alpha_{W}\right) A_{W}+A_{H}\right] \sigma T_{R}^{4}+\left(1-\alpha_{C}\right) A_{C} \sigma T_{R C}^{4}
$$

where

$$
\alpha_{\mathrm{W}} \equiv \frac{\mathrm{P}_{\mathrm{W}}}{\mathrm{A}_{\mathrm{W}} \sigma \mathrm{T}_{\mathrm{R}}^{4}} \quad \alpha_{\mathrm{C}} \equiv \frac{\mathrm{P}_{\mathrm{C}}}{\mathrm{A}_{\mathrm{C}} \sigma \mathrm{T}_{\mathrm{RC}}^{4}}
$$

$P_{C}$ is the total power emitted from the area $A_{C}$.

Since the capsule is convex, $\sigma \mathrm{T}_{\mathrm{RC}}{ }^{4}$ is equal to the flux emitted by the area $\mathrm{A}_{\mathrm{T}}[13,107]$ :

$$
\sigma T_{R C}^{4}=\frac{P_{S}+P_{W}}{A_{S}+A_{W}+A_{H}}=\frac{P_{S}+\alpha_{W} A_{W} \sigma T_{R}^{4}}{A_{T}}
$$

Combining Eqs. 7, 24, and 26 gives

$$
P_{S}=\left[A_{S}+\left(1-\alpha_{W}\right) A_{W}+A_{H}+\left(1-\alpha_{C}\right) A_{C}\left(\frac{\alpha_{W} A_{W}}{A_{T}}\right)\right] \sigma T_{R C}^{4}
$$

and

$$
P_{N}=\left[\left(1-\alpha_{W}\right) A_{W}+A_{H}+\left(1-\alpha_{C}\right) A_{C}\left(\frac{A_{S}+\alpha_{W} A_{W}}{A_{T}}\right)\right] \sigma T_{R C}^{4}
$$

Similar expressions for $P_{S}$ and $P_{N}$ can be obtained as functions of $T_{R}$. From Eq. 28 we obtain the coupling efficiency $\eta_{\text {CAPSULE }}$ of $P_{N}$ to the power absorbed by the capsule:

$$
\eta_{\text {CAPSULE }} \equiv \frac{\left(1-\alpha_{C}\right) A_{C} \sigma T_{R C}^{4}}{P_{N}}=\left[\frac{\left(1-\alpha_{W}\right) A_{W}}{\left(1-\alpha_{C}\right) A_{C}}+\frac{A_{H}}{\left(1-\alpha_{C}\right) A_{C}}+\left(\frac{A_{S}+\alpha_{W} A_{W}}{A_{T}}\right)\right]^{-1}
$$

As $\alpha_{C} \rightarrow 0$ and $A_{C} \rightarrow A_{T}$, then $\eta_{\text {CAPSulE }} \rightarrow 1$, as expected.

Since Eqs. 27-29 account for the source area, hole area, and anisotropic radiation flux in a self-consistent manner, they differ from previous expressions for the radiation drive and capsule-coupling efficiency. (For example, the expression for the coupling efficiency given as Eq. 7.37 in Ref. 51 is derived from Eqs. 7.30 and 7.36. Eq. 7.30 assumes there are holes in the hohlraum wall whereas Eq. 7.36 does not; in addition, Eq. 7.36 assumes 
the source does not directly irradiate the capsule, and that the source area is negligible. However, Eq. 7.37 agrees approximately with Eq. 29 above when $A_{S}, A_{H}<A_{T}$ and $\alpha_{W} \approx$ 1.)

The expression for the coupling efficiency given as Eq. 3.9 in Ref. 13 assumes the source and holes areas are negligible. If we assume (using the notation of Ref. 13) that $\mathrm{P}_{\mathrm{S}_{1}}=$ $\mathrm{A}_{1} \mathrm{P}_{\mathrm{S}} / \mathrm{A}_{2}$; i.e., that the source is uniformly distributed across the cavity wall and is allowed to irradiate the capsule directly, then this expression becomes identical to Eq. 29 above when $A_{S}=A_{H}=0$.

\section{The source indirectly radiates the capsule}

In some ICF concepts involving heavy-ion beams or z-pinches, direct radiation from sources located at both ends of a cylindrical hohlraum is blocked from the capsule by polar x-ray symmetrization shields $[32,49,54,55,64,66]$. (Such shields would, of course, also prevent the sources from receiving direct radiation from the capsule.) For such a system, we make the simplifying assumptions that the area of the shields and $A_{S}$ are much less than $A_{w}$, the radiation flux incident on the source is the same as the flux on the capsule, and the source and capsule are directly irradiated only by power emitted from the region defined by $A_{W}$.

We define $\sigma \mathrm{T}_{\mathrm{RS}}{ }^{4}$ to be the flux incident on $\mathrm{A}_{S}, \sigma \mathrm{T}_{\mathrm{RC}}{ }^{4}$ the flux incident on $\mathrm{A}_{\mathrm{C}}$, and $\sigma \mathrm{T}_{\mathrm{R}}{ }^{4}$ the flux incident on the area $\left(A_{W}+A_{H}\right)$. Under these conditions Eq. 24 and 26 become:

$$
\begin{gathered}
P_{S}=A_{S} \sigma T_{R S}^{4}+\left[\left(1-\alpha_{W}\right) A_{W}+A_{H}\right] \sigma T_{R}^{4}+\left(1-\alpha_{C}\right) A_{C} \sigma T_{R C}^{4} \\
\sigma T_{R C}^{4}=\sigma T_{R S}^{4}=\frac{P_{W}}{A_{W}+A_{H}}=\frac{\alpha_{W} A_{W} \sigma T_{R}^{4}}{A_{W}+A_{H}}
\end{gathered}
$$

Combining Eqs. 30 and 31 gives:

$$
P_{S}-A_{S} \sigma T_{R C}^{4}=P_{N}=\left[\left(\frac{\left(\left(1-\alpha_{W}\right) A_{W}+A_{H}\right)\left(A_{W}+A_{H}\right)}{\alpha_{W} A_{W}}\right)+\left(1-\alpha_{C}\right) A_{C}\right] \sigma T_{R C}^{4}
$$

The capsule coupling efficiency is: 


$$
\eta_{\text {CAPSULE }} \equiv \frac{\left(1-\alpha_{C}\right) A_{C} \sigma T_{R C}^{4}}{P_{N}}=\left[\left(\frac{\left(\left(1-\alpha_{W}\right) A_{W}+A_{H}\right)\left(A_{W}+A_{H}\right)}{\alpha_{W} A_{W}\left(1-\alpha_{C}\right) A_{C}}\right)+1\right]^{-1}
$$

As $\alpha_{C} \rightarrow 0$ and $A_{C} \rightarrow A_{W}+A_{H}$, then $\eta_{\text {CAPSUlE }} \rightarrow \alpha_{W} A_{W} /\left(A_{W}+A_{H}\right)$, as expected.

As noted previously, the expression for the coupling efficiency given as Eq. 3.9 in Ref. 13 assumes the source and holes areas are negligible. If we assume (using the notation of Ref. 13) that $\mathrm{P}_{\mathrm{S} 1}=0$; i.e., that the source is not allowed to irradiate the capsule directly, this expression becomes identical to Eq. 33 above when $A_{S}=A_{H}=0$.

\section{B. Single radiation temperature}

Time-dependent effects are most readily estimated with a simpler, though less-accurate single-radiation-temperature model. If we neglect that the capsule is convex and assume the source irradiates the capsule directly, then $T_{R C}=T_{R}$, and we can generalize the arguments in Section II to obtain:

$$
P_{S}-A_{S} \sigma T_{R}^{4}=P_{N}=\left[\left(1-\alpha_{W}\right) A_{W}+A_{H}+\left(1-\alpha_{C}\right) A_{C}\right] \sigma T_{R}^{4}+\frac{4 V \sigma}{c} \frac{d T_{R}^{4}}{d t}
$$

Eqs. 27, 28, and 32 are consistent with Eq. 34 when $A_{H} \ll A_{W}$ and $\alpha_{W} \approx 1$, since in this limit the flux incident on $A_{T}$ approaches the flux emitted, and $T_{R} \rightarrow T_{R C}$.

The hohlraum time constants become:

$$
\begin{aligned}
& \tau_{H} \equiv \frac{4 V}{c\left[A_{S}+\left(1-\alpha_{W}\right) A_{W}+A_{H}+\left(1-\alpha_{C}\right) A_{C}\right]} \\
& \tau_{H N} \equiv \frac{4 V}{c\left[\left(1-\alpha_{W}\right) A_{W}+A_{H}+\left(1-\alpha_{C}\right) A_{C}\right]} .
\end{aligned}
$$

Other results obtained in Sections II and III follow immediately.

Assuming Eq. 34 and that $\mathrm{dU}_{\mathrm{R}} / \mathrm{dt}$ can be neglected, the capsule-coupling efficiency can be expressed as: 


$$
\eta_{\text {CAPSULE }} \equiv \frac{\left(1-\alpha_{C}\right) A_{C} \sigma T_{R}^{4}}{P_{N}}=\left[\frac{\left(1-\alpha_{W}\right) A_{W}}{\left(1-\alpha_{C}\right) A_{C}}+\frac{A_{H}}{\left(1-\alpha_{C}\right) A_{C}}+1\right]^{-1}
$$

As $A_{H} \rightarrow 0$ and $\alpha_{W} \rightarrow 1$, the efficiencies given by Eqs. 29, 33, and 37 approach 1, since in this limit the only absorber of net power in the hohlraum is the capsule.

\section{HOHLRAUM WITH A CONVEX SOURCE}

\section{A. Two radiation temperatures}

The models in Sections II, III, IV.A.1, and IV.B assume $A_{\mathrm{s}}$ is uniformly distributed across $A_{T}$, and that the source radiates onto itself. If we assume instead that the source is convex, then the source cannot irradiate itself, and the radiation flux incident on the source is, in general, not the same as the flux incident on the rest of the cavity wall.

This approximates a hohlraum that encloses a $\mathrm{z}$ pinch, as is used in some weapon-physics and ICF experiments $[41,43,53,60-62,64,66,69,70,73,76,78,79,81]$. We shall assume the results of this Section are relevant primarily to such a system. We assume the area of the outer hohlraum wall equals $\left(A_{W}+A_{H}+A_{G}\right)$, where $A_{G}$ is the area of the transmission-line gap that feeds power to the pinch. We assume radiation entering the cavity through areas $A_{W}$ and $A_{G}$ is Lambertian. We define $\sigma T_{R S}{ }^{4}$ to be the radiation flux incident on $A_{S}$, and $\sigma \mathrm{T}_{\mathrm{R}}{ }^{4}$ to be the flux incident on the area $\left(\mathrm{A}_{\mathrm{W}}+\mathrm{A}_{\mathrm{H}}+\mathrm{A}_{\mathrm{G}}\right)$. We assume $\sigma \mathrm{T}_{\mathrm{RS}}{ }^{4}$ and $\sigma \mathrm{T}_{\mathrm{R}}{ }^{4}$ are uniform on areas $A_{S}$ and $\left(A_{W}+A_{H}+A_{G}\right)$, respectively.

Under these assumptions Eq. 4 becomes (neglecting $\mathrm{dU}_{\mathrm{R}} / \mathrm{dt}$ ):

$$
P_{S}=A_{S} \sigma T_{R S}^{4}+\left[\left(1-\alpha_{W}\right) A_{W}+A_{H}+\left(1-\alpha_{G}\right) A_{G}\right] \sigma T_{R}^{4}
$$

where

$$
\alpha_{W} \equiv \frac{P_{W}}{A_{W} \sigma T_{R}^{4}} \quad \alpha_{G} \equiv \frac{P_{G}}{A_{G} \sigma T_{R}^{4}}
$$

$\alpha_{G}$, the effective albedo of area $A_{G}$, is not zero because radiation scatters from the walls of the transmission line back into the hohlraum $[60,70,76] . P_{G}$ is the total power that 
scatters into the hohlraum through area $A_{G}$.

Since the source is convex, $\sigma \mathrm{T}_{\mathrm{RS}}{ }^{4}$ is equal to the flux emitted by the region defined by the area $\left(A_{W}+A_{H}+A_{G}\right)[13,107]$ :

$$
\sigma T_{R S}^{4}=\frac{P_{W}+P_{G}}{A_{W}+A_{H}+A_{G}}=\frac{\left(\alpha_{W} A_{W}+\alpha_{G} A_{G}\right) \sigma T_{R}^{4}}{A_{W}+A_{H}+A_{G}}
$$

Combining Eqs. 38 and 40 gives

$$
P_{S}=\left[A_{S}\left(\frac{\alpha_{W} A_{W}+\alpha_{G} A_{G}}{A_{W}+A_{H}+A_{G}}\right)+\left(1-\alpha_{W}\right) A_{W}+A_{H}+\left(1-\alpha_{G}\right) A_{G}\right] \sigma T_{R}^{4}
$$

Since $P_{N}=P_{S}-A_{S} \sigma T_{R S}{ }^{4}$, we have from Eq. 38:

$$
P_{N}=\left[\left(1-\alpha_{W}\right) A_{W}+A_{H}+\left(1-\alpha_{G}\right) A_{G}\right] \sigma T_{R}^{4}
$$

Similar expressions for $P_{S}$ and $P_{N}$ can be obtained as functions of $T_{R S}$.

\section{B. Single radiation temperature}

If we neglect that the source is convex and assume $\mathbb{T}_{R S}=T_{R}$, we can generalize the arguments in Section II to obtain a single-radiation-temperature model of a hohlraum containing a $\mathrm{z}$ pinch:

$$
P_{S}-A_{S} \sigma T_{R}^{4}=P_{N}=\left[\left(1-\alpha_{W}\right) A_{W}+A_{H}+\left(1-\alpha_{G}\right) A_{G}\right] \sigma T_{R}^{4}+\frac{4 V \sigma}{c} \frac{d T_{R}^{4}}{d t}
$$

Eqs. 41 and 42 are consistent with Eq. 43 when $A_{H}, A_{G} \ll A_{W}$ and $\alpha_{W} \approx 1$, since in this limit the flux incident on $\left(A_{W}+A_{H}+A_{G}\right)$ approaches the flux emitted by this area, and $T_{R}$ $\rightarrow \mathrm{T}_{\mathrm{RS}}$.

The hohlraum time constants become:

$$
\tau_{H} \equiv \frac{4 V}{c\left[A_{S}+\left(1-\alpha_{W}\right) A_{W}+A_{H}+\left(1-\alpha_{G}\right) A_{G}\right]}
$$




$$
\tau_{H N} \equiv \frac{4 V}{c\left[\left(1-\alpha_{W}\right) A_{W}+A_{H}+\left(1-\alpha_{G}\right) A_{G}\right]}
$$

Other results obtained in Sections II and III follow immediately.

\section{Z-PINCH-SOURCE MODEL}

A. $P_{S}$ as a function of geometry

In principle $\mathrm{P}_{\mathrm{S}}$ can be measured through a small diagnostic hole in the hohlraum wall. Because of aperture closure it is more convenient to measure the source power in a system with large diagnostic apertures. However, large apertures lower the radiation temperature in a hohlraum, which decreases the heating of the source and hence the source temperature and total source power $\mathrm{P}_{\mathrm{s}}$. For a z-pinch source, a simple model can be used to estimate the effect of hohlraum geometry on $P_{S}$.

We consider a z-pinch at stagnation and model it as a convex blackbody with constant volume. We estimate the time rate of change of the pinch's internal energy $U_{s}$ as:

$$
\frac{d U_{S}}{d t}=P_{E X T}+A_{S} \sigma T_{R S}^{4}-P_{S}=P_{E X T}-P_{N}
$$

where $P_{E X T}$ is the external source of power delivered to the pinch, and $\sigma T_{R S}{ }^{4}$ is the radiation flux incident on the source. In a geometry with large diagnostic apertures:

$$
\frac{d U_{S L}}{d t}=P_{E X T}+A_{S} \sigma T_{R S L}^{4}-P_{S L}=P_{E X T}-P_{N L}
$$

where the subscript " $L$ " denotes quantities for the large-aperture system. (We assume $\mathrm{P}_{\mathrm{EXT}}$ is independent of geometry.) When $\mathrm{dU}_{\mathrm{R}} / \mathrm{dt}, \mathrm{dU}_{\mathrm{S}} / \mathrm{dt}$, and $\mathrm{dU}_{\mathrm{SL}} / \mathrm{dt}$ can be neglected, we can combine Eqs. $41,42,46$, and 47 to obtain:

$$
\mathrm{gP}_{\mathrm{S}}=\mathrm{P}_{\mathrm{N}}=\mathrm{P}_{\mathrm{NL}}=\mathrm{g}_{\mathrm{L}} \mathrm{P}_{\mathrm{SL}}
$$

where 


$$
g \equiv \frac{\left(1-\alpha_{W}\right) A_{W}+A_{H}+\left(1-\alpha_{G}\right) A_{G}}{A_{S}\left(\frac{\alpha_{W} A_{W}+\alpha_{G} A_{G}}{A_{W}+A_{H}+A_{G}}\right)+\left(1-\alpha_{W}\right) A_{W}+A_{H}+\left(1-\alpha_{G}\right) A_{G}}
$$

is calculated for the hohlraum without the large diagnostic apertures, and $\mathrm{g}_{\mathrm{L}}$ is the corresponding quantity for the large-aperture system. Eq. 48 gives the total- and netsource terms $P_{S}$ and $P_{N}$ as a function of $P_{S L}$. (We have implicitly assumed the apertures used to measure $\mathrm{P}_{\mathrm{SL}}$ do not affect pinch performance.) According to Eq. 48, the total power $\mathrm{P}_{\mathrm{S}}$ emitted by a $\mathrm{z}$ pinch in the hohlraum without the large apertures is greater by the factor $\left(\mathrm{g}_{\mathrm{L}} / \mathrm{g}\right)$.

\section{B. Source time constant}

Eq. 48 assumes $\mathrm{dU}_{\mathrm{R}} / \mathrm{dt}, \mathrm{dU}_{\mathrm{S}} / \mathrm{dt}$, and $\mathrm{dU}_{\mathrm{SL}} / \mathrm{dt}$ can be neglected. We can assume $\mathrm{dU}_{\mathrm{R}} / \mathrm{dt}=0$ when the time of interest is much longer than the hohlraum time constant, i.e., the time required to fill the hohlraum with radiation. We can set $\mathrm{dU}_{\mathrm{S}} / \mathrm{dt}=\mathrm{dU}_{\mathrm{SL}} / \mathrm{dt}=0$ when the time of interest is much longer than the time required by the radiation to heat the $\mathrm{z}$-pinch source to its equilibrium temperature.

An estimate of the hohlraum time constant is given as Eq. 45. To estimate the z-pinchsource time constant, we make the simplifying assumption that the hohlraum time constant can be neglected, and set $\mathrm{dU}_{\mathrm{R}} / \mathrm{dt}=0$. Combining Eqs. $41,42,46$, and 47 , we obtain:

$$
\frac{d U_{S}}{d t}-\frac{d U_{S L}}{d t}=P_{N L}-P_{N}=g L P_{S L}-g P_{S}
$$

To develop an expression for $\mathrm{U}_{\mathrm{S}}$, we assume the $\mathrm{z}$ pinch can be modeled as a plasma with ion-charge state $Z \gg>1$, and that $U_{s}$ is dominated by the kinetic energy of electrons and potential energy of ions [108]. Hence:

$$
U_{S}=\frac{3}{2} N Z k T_{S}+N \sum_{j=1}^{Z} I_{j}=\frac{3}{2} N Z k T_{S}+N Z I_{A V E}=(0.042) N k T_{S}^{3 / 2} \equiv \beta T_{S}^{3 / 2}
$$

where $\mathrm{N}$ is the number of ions, $\mathrm{k}$ is the Boltzmann constant, $\mathrm{I}_{\mathrm{J}}$ is the jth ionization potential, and $\mathrm{I}_{\mathrm{AVE}}$ is the average of the first $\mathrm{Z}$ ionization potentials. Eq. 51 sets $\mathrm{Z}=$ $(0.014) \mathrm{T}_{\mathrm{S}}^{1 / 2}$ and $\mathrm{I}_{\mathrm{AVE}}=3 \mathrm{kT}_{\mathrm{S}} / 2\left(\mathrm{~T}_{\mathrm{S}}\right.$ in degrees Kelvin), which are reasonable 
approximations for a high-atomic-number z-pinch at electron densities $\left(10^{28} \mathrm{~m}^{-3}\right)$ and temperatures $\left(2 \times 10^{6} \mathrm{~K}\right)$ of interest $[109,110]$. Similarly, $\mathrm{U}_{\mathrm{SL}}=\beta \mathrm{T}_{\mathrm{SL}}{ }^{3 / 2}$. Combining these expressions for internal energy with Eq. 50 (and assuming $A_{S}=A_{S L}$ ) gives

$$
\frac{3}{2} \beta\left(T_{S}^{1 / 2} \frac{d T_{S}}{d t}-T_{S L}^{1 / 2} \frac{d T_{S L}}{d t}\right)=A_{S} \sigma\left(g_{L} T_{S L}^{4}-h T_{S}^{4}\right)
$$

Assuming $\mathrm{T}_{\mathrm{S}}{ }^{4}=\mathrm{T}_{\mathrm{SL}}{ }^{4}(1+\mathrm{f})$ where $0 \leq \mathrm{f} \ll 1, \mathrm{f}(\mathrm{t}=0)=0$, and $\mathrm{T}_{\mathrm{SL}}=\gamma \mathrm{t}^{\mathrm{n}}$ where $\gamma$ is a positive constant and $\mathrm{n}$ is non-negative integer, we find (neglecting terms second and higher order in $f$ ):

$$
\frac{d f}{d t}+\left[\left(\frac{3 n}{2 t}\right)+\left(\frac{8 A_{S} \sigma g}{3 \beta}\right) \gamma^{5 / 2} t^{5 n / 2}\right] f=\frac{8 A_{S} \sigma\left(g_{L}-g\right)}{3 \beta} \gamma^{5 / 2} t^{5 n / 2}
$$

When $n \geq 0$ and $t>>[3 n /(5 n+2)]^{2 /(5 n+2)} \tau_{s}$ :

$$
f(t)=\frac{g_{L}-g}{g}\left\{1-\exp \left[-\left(\frac{t}{\tau_{s}}\right)^{\frac{5 n+2}{2}}\right]\right\}
$$

where the source time constant $\tau_{\mathrm{S}}$ is defined by

$$
\tau_{s} \equiv\left[\frac{3 \beta(5 n+2)}{16 A_{s} \sigma g \gamma^{5 / 2}}\right]^{\frac{2}{5 n+2}}
$$

As $t \rightarrow \infty, f \rightarrow f_{S} \equiv\left(g_{L}-g\right) / g$ where $f_{s}$ is the steady-state value of $f$. In this limit $T_{s}^{4} \rightarrow$ $\mathrm{T}_{\mathrm{SL}}{ }^{4}\left(1+\mathrm{f}_{\mathrm{S}}\right)=\mathrm{T}_{\mathrm{SL}}{ }^{4}\left(\mathrm{~g}_{\mathrm{L}} / \mathrm{g}\right)$, and (according to Eq. 48$) \mathrm{P}_{\mathrm{N}} \rightarrow \mathrm{P}_{\mathrm{NL}}$.

We define 1- $\varepsilon$ to be the ratio of $P_{S}$ as determined by Eq. 50 , to $P_{S}$ as determined by Eq. 48 ; hence the fractional error $\varepsilon$ is given by:

$$
\varepsilon \equiv \frac{\left(\frac{g_{L} P_{S L}}{g}\right)-P_{S L}(1+f)}{\left(\frac{g_{L} P_{S L}}{g}\right)}=\left(\frac{g_{L}-g}{g_{L}}\right) \exp \left[-\left(\frac{t}{\tau_{S}}\right)^{\frac{5 n+2}{2}}\right]
$$

The maximum value of $\varepsilon$ equals $\left(\mathrm{g}_{\mathrm{L}}-\mathrm{g}\right) / \mathrm{g}_{\mathrm{L}}$ and occurs when $\mathrm{t}=0$. 


\section{NIF AND Z-ACCELERATOR HOHLRAUMS}

The baseline NIF hohlraum $[28,33,35,40,50,51,63,80]$ can be modeled as described in Section IV.A.1. For this system $A_{S}=4.0 \times 10^{-5} \mathrm{~m}^{2}, A_{w}=1.6 \times 10^{-4} \mathrm{~m}^{2}, A_{H}=1.2 \times 10^{-5}$ $\mathrm{m}^{2}, \mathrm{~A}_{\mathrm{C}} \sim 6 \times 10^{-6} \mathrm{~m}^{2}, \alpha_{\mathrm{w}}=0.89$, and $\alpha_{\mathrm{C}} \sim 0$ [35]. Assuming a $75 \%$ laser-conversion efficiency [35] and $P_{\text {LASER }}=400$ TW [28,33,51], Eqs. 11 and 28 predict the capsule-drive temperature $T_{R C}$ would be $303 \mathrm{eV}$. The value predicted by integrated calculations is 300 $\mathrm{eV}[28,33,51]$. According to Eq. $29, \eta_{\mathrm{CAPSULE}}=17 \%$, which is $15 \%$ higher than predicted by previous analytic relations.

The standard z-pinch-driven hohlraum fielded on the $Z$ accelerator $[53,61,73,76,102]$ can be modeled as described in Sections $V$ and VI. For this system, $A_{s} \approx 6 \times 10^{-5} \mathrm{~m}^{2}, A_{W}=$ $1.50 \times 10^{-3} \mathrm{~m}^{2}, \mathrm{~A}_{\mathrm{H}}=5.65 \times 10^{-5} \mathrm{~m}^{2}$, and $\mathrm{V}=4.5 \times 10^{-6} \mathrm{~m}^{3}$. Because of gap closure we estimate from experiments conducted on $\mathrm{Z}$ that $\mathrm{A}_{\mathrm{G}} \approx 6.9 \times 10^{-5} \mathrm{~m}^{2}, 50 \%$ of its initial value. Assuming $\mathrm{T}_{\mathrm{w}}$ peaks for $3 \mathrm{~ns}$ at $128 \mathrm{eV}$ (as discussed below) and Rosen's albedo model $[1,29,35,51,84]$, we obtain that at peak temperature $\alpha_{\mathrm{w}}=0.85$. According to calculations by Vesey $[60,70,76], \alpha_{G} \approx 0.34$. Hence according to Eq. $49, g=0.87$.

To estimate $P_{S}$ we use measurements of $P_{S L}$ made on shots taken with nine large diagnostic apertures in the hohlraum wall. For this system the average value of $P_{S L}$ is approximately $110 \mathrm{TW}$ [111] and $g_{L}=0.97$. Consequently from Eq. 48 we have $P_{S}=$ $\left(\mathrm{g}_{\mathrm{L}} / \mathrm{g}\right) \mathrm{P}_{\mathrm{SL}}=122 \mathrm{TW}$. Using this value and Eq. 41 , we estimate that in the standard hohlraum system (without the large diagnostic apertures) $T_{R}$ peaks at $133 \mathrm{eV}$, and (from Eq. 5) the wall temperature $T_{w}=\left(\alpha_{w}\right)^{1 / 4} T_{R}=128 \mathrm{eV}$. The measured value of $T_{w}$ is $133 \pm$ $7 \mathrm{eV}[111]$.

From Eq. 44 we estimate that during the 5-ns rise of the $\mathrm{x}$-ray power pulse, $\tau_{\mathrm{H}} \sim 0.1 \mathrm{~ns}$. Assuming $\mathrm{P}_{\mathrm{S}} \propto \mathrm{t}^{4}$ (the source temperature is approximately proportional to $\mathrm{t}$ ) during this time, we use Eqs. 15 and 17 to find $\delta=100 \%$ at $\mathrm{t}=0$, and $8 \%$ at $\mathrm{t}=5 \mathrm{~ns}$. According to Eq. $55, \tau_{\mathrm{s}}=2.6 \mathrm{~ns}$; hence from Eq. 56 we estimate that $\varepsilon=10 \%$ at $\mathrm{t}=0$, and is negligible at $5 \mathrm{~ns}$. Assuming that afterward $\mathrm{P}_{\mathrm{S}}$ and $\mathrm{T}_{\mathrm{SL}}$ are to a good approximation constant for 3 ns at peak power, we estimate with Eqs. 13 and 56 that during most of this interval $\delta$ and $\varepsilon$ are negligible. 
The 4-mm-diameter 4-mm-high static-wall hohlraum fielded on the $\mathrm{Z}$ accelerator by Sanford et. al. [79] can be modeled as described in Section II. For this system $A_{S}=1.26$ $\times 10^{-5} \mathrm{~m}^{2}, A_{W}=5.97 \times 10^{-5} \mathrm{~m}^{2}, A_{H}=3.14 \times 10^{-6} \mathrm{~m}^{2}$, and $P_{S} \sim 13 \mathrm{TW}$. Assuming $T_{W}$ peaks at $146 \mathrm{eV}$ (as discussed below) for $3 \mathrm{~ns}$ and Rosen's albedo model [1,29,35,51,84], we estimate that at peak temperature $\alpha_{w}=0.86$. Using Eqs. 5 and 10 , we find $T_{R}$ and $T_{W}$ are expected to peak at $151 \mathrm{eV}$ and $146 \mathrm{eV}$, respectively. The measured value [79] of $\mathrm{T}_{\mathrm{w}}$ midway between the top and bottom of the hohlraum is $155 \pm 8 \mathrm{eV}$.

\section{ACKNOWLEDGMENTS}

The authors wish to thank L. P. Mix for reviewing this article, G. A. Chandler, M. E. Cuneo, D. L. Fehl, H. C. Ives, D. H. McDaniel, L. P. Mix, J. J. Ramirez, J. F. Seamen, R. A. Vesey, and T. C. Wagoner for critical technical discussions, M. E. Cuneo, J. L. Porter, P. H. Primm, L. E. Ruggles, W. W. Simpson, and D. F. Wenger for providing hohlraumwall-temperature measurements, G. A. Chandler, M. E. Cuneo, D. L. Fehl, J. L. Porter, J. J. Seamen, P. H. Primm, L. E. Ruggles, W. W. Simpson, J. A. Torres, and D. F. Wenger for pinch-power measurements, and R. A. Vesey for albedo calculations.

Sandia is a multiprogram laboratory operated by Sandia Corporation, a Lockheed Martin Company, for the United States Department of Energy under contract DE-AC0494AL85000.

[1] M. D. Rosen (unpublished, 1979).

[2] P. Herrmann, R. Pakula, I. B. Földes, R. Sigel, G. D. Tsakiris, and S. Witkowski, Z. Naturforsch 41a, 767 (1986).

[3] R. Pakula and R. Sigel, Z. Naturforsch. 41a, 463 (1986).

[4] T. Mochizuki, T. Yabe, H. Azechi, K. Tanaka, T. Boehly, N. Miyanaga, H. Nishimura, S. Ido, M. Yamanaka, K. Nishihara, T. Norimatsu, T. Jitsuno, M. Nakatsuka, K. Mima, S. Nakai, C. Yamanaka, R. Sigel, G. D. Tsakiris, K. Eidmann, P. Herrmann, R. Pakula, P. Sachsenmaier, S. Sakabe, S. Witkowski, Nuclear Fusion Supplement 3, 25 (1987).

[5] S. Sakabe, R. Sigel, G. D. Tsakiris, I. B. Földes, and P. Herrmann, Phys. Rev. A 38, 5756 (1988).

[6] R. Sigel, R. Pakula, S. Sakabe, and G. D. Tsakiris, Phys. Rev. A 38, 5779 (1988). 
[7] G. D. Tsakiris and R. Sigel, Phys. Rev. A 38, 5769 (1988).

[8] K. Kondo, H. Nishimura, H. Sakurai, K. Nishihara, Y. Izawa, Y. Kato, C. Yamanaka, and S. Nakai, Jpn. J. Appl. Phys. 28, 1695 (1989).

[9] R. Sigel, G. D. Tsakiris, F. Lavarenne, J. Massen, R. Fedosejevs, J. Meyer-ter-Vehn, M. Murakami, K. Eidmann, S. Witkowski, H. Nishimura, Y. Kato, H. Takabe, T. Endo, K. Kondo, H. Shiraga, S. Sakabe, T. Jitsuno, M. Takagi, C. Yamanaka, and S. Nakai, Phys. Rev. Lett. 65, 587 (1990).

[10] G. D. Tsakiris, J. Massen, R. Sigel, F. Lavarenne, R. Fedosejevs, J. Meyer-ter-Vehn, K. Eidmann, S. Witkowski, H. Nishimura, Y. Kato, H. Takabe, T. Endo, K. Kondo, H. Shiraga, S. Sakabe, T. Jitsuno, M. Takagi, C. Yamanaka, and S. Nakai, Phys. Rev. A 42, 6188 (1990).

[11] E. M. Campbell, Laser Part. Beams 9, 209 (1991).

[12] K. Kondo, H. Nishimura, Y. Kato, and S. Nakai, Jpn. J. Appl. Phys. 30, 839 (1991).

[13] M. Murakami and J. Meyer-ter-Vehn, Nucl. Fusion 31, 1315 (1991).

[14] H. Nishimura, Y. Kato, H. Takabe, T. Endo, K. Kondo, H. Shiraga, S. Sakabe, T. Jitsuno, M. Takagi, C. Yamanaka, S. Nakai, R. Sigel, G. D. Tsakiris, J. Massen, M. Murakami, F. Lavarenne, R. Fedosejevs, J. Meyer-ter-Vehn, K. Eidmann, and S. Witkowski, Phys. Rev. A 44, 8323 (1991).

[15] V. P. Smirnov, Plasma Phys. Controlled Fusion 33, 1697 (1991).

[16] R. Sigel, G. D. Tsakiris, F. Lavarenne, J. Massen, R. Fedosejevs, K. Eidmann, J. Meyer-ter-Vehn, M. Murakami, S. Witkowski, H. Nishimura, Y. Kato, H. Takabe, T. Endo, K. Kondo, H. Shiraga, S. Sakabe, T. Jitsuno, M. Takagi, S. Nakai, and C. Yamanaka, Phys. Rev. A 45, 3987 (1992).

[17] R. Cauble, D. W. Phillion, T. J. Hoover, N. C. Holmes, J. D. Kilkenny, and R. W. Lee, Phys. Rev. Lett. 70, 2102 (1993).

[18] J. Massen, G. D. Tsakiris, and R. Sigel, Phys. Rev. E 48, 2073 (1993).

[19] M. D. Rosen, Lawrence Livermore National Laboratory Report UCRL-ID-119916 (1993).

[20] R. Sigel, H. Baumhacker, G. Brederlow, K. Eidmann, E. Fill, J. Massen, J. Meyerter-Vehn, W. Schwanda, Ch. Stöckl, G. D. Tsakiris, R. Volk, S. Witkowski, and K. J. Witte, Laser Particle Beams 11, 167 (1993).

[21] M. D. Cable, S. P. Hatchett, J. A. Caird, J. D. Kilkenny, H. N. Kornblum, S. M. Lane, C. Laumann, R. A. Lerche, T. J. Murphy, J. Murray, M. B. Nelson, D. W. Phillion, H. Powell, and D. B. Ress, Phys. Rev. Lett. 73, 2316 (1994).

[22] T. R. Dittrich, B. A. Hammel, C. J. Keane, R. McEachern, R. E. Turner, S. W. Haan, and L. J. Suter, Phys. Rev. Lett. 73, 2324 (1994).

[23] D. D.-M. Ho, J. D. Lindl, and M. Tabak, Nucl. Fusion 34, 1081 (1994). 
[24] R. L. Kauffman, L. J. Suter, C. B. Darrow, J. D. Kilkenny, H. N. Kornblum, D. S. Montgomery, D. W. Phillion, M. D. Rosen, A. R. Thiessen, R. J. Wallace, and F. Ze, Phys. Rev. Lett. 73, 2320 (1994).

[25] Th. Löwer, R. Sigel, K. Eidmann, I. B. Földes, S. Hüller, J. Massen, G. D. Tsakiris, S. Witkowski, W. Preuss, H. Nishimura, H. Shiraga, Y. Kato, S. Nakai, and T. Endo, Phys. Rev. Lett. 72, 3186 (1994).

[26] J. Massen, G. D. Tsakiris, K. Eidmann, I. B. Földes, Th. Löwer, R. Sigel, S.

Witkowski, H. Nishimura, T. Endo, H. Shiraga, M. Takagi, Y. Kato, and S. Nakai, Phys. Rev. E 50, 5130 (1994).

[27] L. J. Suter, A. A. Hauer, L. V. Powers, D. B. Ress, N. Delameter, W. W. Hsing, O.

L. Landen, A. R. Thiessen, and R. E. Turner, Phys. Rev. Lett. 73, 2328 (1994).

[28] S. W. Haan, S. M. Pollaine, J. D. Lindl, L. J. Suter, R. L. Berger, L. V. Powers, W. E. Alley, P. A. Amendt, J. A. Futterman, W. K. Levedahl, M. D. Rosen, D. P. Rowley, R. A. Sacks, A. I. Shestakov, G. L. Strobel, M. Tabak, S. V. Weber, G. B. Zimmerman, W. J. Krauser, D. C. Wilson, S. V. Coggeshall, D. B. Harris, N. M. Hoffman, and B. H. Wilde, Phys. Plasmas 2, 2480 (1995).

[29] M. D. Rosen, Lawrence Livermore National Laboratory report UCRL-JC-121585 (1995).

[30] K. S. Budil, B. A. Remington, T. A. Peyser, K. O. Mikaelian, P. L. Miller, N. C. Woolsey, W. M. Wood-Vasey, and A. M. Rubenchik, Phys. Rev. Lett. 76, 4536 (1996).

[31] M. S. Derzon, G. A. Chandler, R. J. Dukart, D. J. Johnson, R. J. Leeper, M. K. Matzen, E. J. McGuire, T. A. Mehlhorn, A. R. Moats, R. E. Olson, and C. L. Ruiz, Phys. Rev. Lett. 76, 435 (1996).

[32] K. H. Kang, N. A. Tahir, and J. A. Maruhn, Plasma Phys. Contrl. Fusion 38, 165 (1996).

[33] W. J. Krauser, N. M. Hoffman, D. C. Wilson, B. H. Wilde, W. S. Varnum, D. B. Harris, F. J. Swenson, P. A. Bradley, S. W. Haan, S. M. Pollaine, A. S. Wan, J. C. Moreno, and P. A. Amendt, Phys. Plasmas 3, 2084 (1996).

[34] T. J. Orzechowski, M. D. Rosen, H. N. Kornblum, J. L. Porter, L. J. Suter, A. R. Thiessen, and R. J. Wallace, Phys. Rev. Lett. 77, 3545 (1996).

[35] M. D. Rosen, Phys. Plasmas 3, 1803 (1996), and references therein.

[36] L. J. Suter, R. L. Kaufmann, C. B. Darrow, A. A. Hauer, H. Kornblum, O. L. Landen, T. J. Orzechowski, D. W. Phillion, J. L. Porter, L. V. Powers, A. Richard, M. D. Rosen, A. R. Thiessen, and R. Wallace, Phys. Plasmas 3, 2057 (1996).

[37] J. P. Apruzese, R. W. Clark, J. Davis, and P. C. Kepple, Phys. Rev. Lett. 79, 3190 (1997). 
[38] C. Decker, R. E. Turner, O. L. Landen, L. J. Suter, P. Amendt, H. N. Kornblum, B. A. Hammel, T. J. Murphy, J. Wallace, N. D. Delamater, P. Gobby, A. A. Hauer, G. R. Magelssen, J. A. Oertel, J. Knauer, F. J. Marshall, D. Bradley, W. Seka, and J. M. Soures, Phys. Rev. Lett., 79, 1491 (1997).

[39] M. S. Derzon, T. J. Nash, G. O. Allshouse, A. J. Antolak, C. Deeney, M. Hurst, J. S. McGurn, D. J. Muron, J. F. Seamen, J. MacFarlane, T. Demiris, L. Hrubesh, H. Lewis, D. Ryutov, T. Barber, T. Gilliland, D. Jobe, and S. Lazier, Rev. Sci. Instrum. 68, 848 (1997).

[40] T. R. Dittrich, S. W. Haan, S. Pollaine, A. K. Burnham, and G. L. Strobel, Fusion Technology 31, 402 (1997).

[41] M. K. Matzen, Phys. Plasmas 4, 1519 (1997).

[42] J. Meyer-ter-Vehn, Plasma Phys. Control. Fusion 39, B39 (1997).

[43] R. E. Olson, J. L. Porter, G. A. Chandler, D. L. Fehl, D. O. Jobe, R. J. Leeper, M. K. Matzen, J. S. McGurn, D. D. Noack, L. E. Ruggles, P. Sawyer, J. A. Torres, M. Vargas, D. M. Zagar, H. N. Kornblum, T. J. Orzechowski, D. W. Phillion, L. J. Suter, A. R. Thiessen, and R. J. Wallace, Phys. Plasmas 4, 1818 (1997).

[44] F. Ze, S. H. Langer, R. L. Kauffman, J. D. Kilkenny, O. Landen, D. Ress, M. D. Rosen, L. J. Suter, R. J. Wallace, and J. D. Wiedwald, Phys. Plasmas 4, 778 (1997).

[45] J. Brownell, R. L. Bowers, K. D. McLenithan, and D. L. Peterson, Phys. Plasmas 5, 207 (1998).

[46] D. Colombant, M. Klapsich, and A. Bar-Shalom, Phys. Rev. E 57, 3411 (1998).

[47] T. R. Dittrich, S. W. Haan, M. M. Marinak, S. M. Pollaine, and R. McEachern, Phys. Plasmas 5, 3708 (1998).

[48] S. H. Glenzer, L. J. Suter, R. E. Turner, B. J. MacGowan, K. G. Estabrook, M. A. Blain, S. N. Dixit, B. A. Hammel, R. L. Kauffman, R. K. Kirkwood, O. L. Landen, M.-C. Monteil, J. D. Moody, T. J. Orzechowski, D. M. Pennington, G. F. Stone, and T. L. Weiland, Phys. Rev. Lett. 80, 2845 (1998).

[49] D. D.-M. Ho, J. A. Harte, and M. Tabak, Nucl. Fusion 38, 701 (1998).

[50] H. Hora, H. Azechi, Y. Kitagawa, K. Mima, M. Murakami, S. Nakai, K. Nishihara, H. Takabe, C. Yamanaka, M. Yamanaka, and T. Yamanaka, J. Plasma Physics 60, 743 (1998).

[51] J. D. Lindl, Inertial Confinement Fusion (Springer-Verlag, New York, 1998).

[52] T. J. Murphy, J. M. Wallace, N. D. Delamater, Cris W. Barnes, P. Gobby, A. A. Hauer, E. L. Lindman, G. Magelssen, J. B. Moore, J. A. Oertel, R. Watt, O. L. Landen, P. Amendt, M. Cable, C. Decker, B. A. Hammel, J. A. Koch, L. J. Suter, R. E. Turner, R. J. Wallace, F. J. Marshall, D. Bradley, R. S. Craxton, R. Keck, J. P. Knauer, R. Kremens, and J. D. Schnittman, Phys. Plasmas 5, 1960 (1998). [53] J. L. Porter, Bull. Am. Phys. Soc. 42, 1948 (1998). 
[54] R. Ramis, J. Ramírez, J. J. Honrubia, J. Meyer-ter-Vehn, A. R. Piriz, J. Sanz, L. F. Ibáñez, M. M. Sánchez and M. de laTorre, Nucl. Instr. and Meth. in Phys. Res. A 415, 93 (1998).

[55] G. N. Remizov, Yu. A. Romanov, N. A. Ryabikina, R. M. Shagaliev, L. L. Vakhlamova, V. V. Vatulin, O. A. Vinokurov, R. Bock, K. -H. Kang and J. A. Maruhn, Nucl. Instr. and Meth. in Phys. Res. A 415, 139 (1998).

[56] M. Tabak, D. Callahan-Miller, D. D.-M. Ho, and G. B. Zimmerman, Nucl. Fusion 38, 509 (1998).

[57] M. Tabak and D. A. Callahan-Miller, Phys. Plasmas 5, 1895 (1998).

[58] M. Tabak and D. Callahan-Miller, Nucl. Instr. and Meth. in Phys. Res. A 415, 75 (1998).

[59] G. Velarde, J. M. Perlado, E. Alonso, M. D. Cobo, A. Crisol, L. Doreste, J. M. Gil, L. Gonzalez, J. Honrubia, L. F. Ibanez, P. Martel, E. Minguez, J. M. Martinez-Val, F. Ogando, M. Piera, R. Piriz, J. Ramirez, R. Ramis, J. G. Rubiano, M. Sanchez, J. Sanz, G. J. Sanz, and P. Velarde, Nucl. Instr. and Meth. in Phys. Res. A 415, 35 (1998).

[60] R. A. Vesey and T. A. Mehlhorn, Bull. Amer. Phys. Soc. 43, 1903 (1998).

[61] K. L. Baker, J. L. Porter, L. E. Ruggles, G. A. Chandler, C. Deeney, M. Vargas, A. Moats, K. Struve, J. Torres, J. McGurn, W. W. Simpson, D. L. Fehl, R. E. Chrien, W. Matuska, and G. C. Idzorek, Appl. Phys. Lett. 75, 775 (1999).

[62] J. H. Hammer, M. Tabak, S. C. Wilks, J. D. Lindl, D. S. Bailey, P. W. Rambo, A. Toor, G. B. Zimmerman, and J. L. Porter, Jr., Phys. Plasmas 6, 2129 (1999).

[63] J. D. Kilkenny, T. P. Bernat, B. A. Hammel, R. L. Kauffman, O. L. Landen, J. D. Lindl, B. J. MacGowan, J. A. Paisner, and H. T. Powell, Laser Particle Beams 17, 159 (1999).

[64] R.J. Leeper et al., Nuclear Fusion, 39,1283 (1999).

[65] T. J. Nash, M. S. Derzon, G. A. Chandler, R. Leeper, D. Fehl, J. Lash, C. Ruiz, G. Cooper, J. F. Seamen, J. McGurn, S. Lazier, J. Torres, D. Jobe, T. Gilliland, M. Hurst, R. Mock, P. Ryan, D. Nielsen, J. Armijo, J. McKenney, R. Hawn, D. Hebron, J. J. MacFarlane, D. Peterson, R. Bowers, W. Matuska, and D. D. Ryotov, Phys. Plasmas 6, 2023 (1999).

[66] R. E. Olson, G. A. Chandler, M. S. Derzon, D. E. Hebron, J. S. Lash, R. J. Leeper, T. J. Nash, G. E. Rochau, T. W. L. Sanford, N. B. Alexander, and C. R. Gibson, Fusion Technology 35, 260 (1999).

[67] W. Pei, T. Chang, G. Wang, X. Zhang, C. Sui, and J. Zhang, Phys. Plasmas 6, 3337 (1999).

[68] M. D. Rosen, Phys. Plasmas 6, 1690 (1999). 
[69] T. W. L. Sanford, R. E. Olson, R. L. Bowers, G. A. Chandler, M. S. Derzon, D. E. Hebron, R. J. Leeper, R. C. Mock, T. J. Nash, D. L. Peterson, L. E. Ruggles, W. W. Simpson, K. W. Struve, and R. A. Vesey, Phys. Rev. Lett. 83, 5511 (1999).

[70] R. A. Vesey, M. Cuneo, D. Hanson, J. Porter, T. Mehlhorn, L. Ruggles, W. Simpson, M. Vargas, J. Hammer, and O. Landen, Bull. Amer. Phys. Soc. 44, No. 7, 227 (1999).

[71] J. M. Wallace, T. J. Murphy, N. D. Delamater, K. A. Klare, J. A. Oertel, G. R. Magelssen, E. L. Lindman, A. A. Hauer, P. L. Gobby, J. D. Schnittman, R. S. Craxton, W. Seka, R. Kremens, D. Bradley, S. M. Pollaine, R. E. Turner, O. L. Landen, D. Drake, and J. J. MacFarlane, Phys. Rev. Lett. 82, 3807 (1999).

[72] K. Witte, M. Basko, H. Baumhacker, A. Böswald, K. Eidmann, R. Fedosejevs, E. Fill, V. Kondrashov, A. Kendl, T. Löwer, Y. Li, P. X. Lu, J. Meyer-ter-Vehn, G. Pretzler, A. Saemann, R. Sigel, G. Tsakiris, X. Wang, A. Benuzzi, B. Faral, C. Chenais-Popovics, M. Koenig, H. Merdji, D. Batani, D. Beretta, C. Danson, and T. Hall, Fusion Engineering and Design 44, 147 (1999).

[73] K. L. Baker, J. L. Porter, L. E. Ruggles, G. A. Chandler, C. Deeney, M. Vargas, A. Moats, K. Struve, J. Torres, J. S. McGurn, W. W. Simpson, D. L. Fehl, D. O. Jobe, R. E. Chrien, W. Matuska, and G. C. Idzorek, Phys. Plasmas 7, 681 (2000).

[74] G. R. Bennett, J. M. Wallace, T. J. Murphy, R. E. Chrien, N. D. Delamater, P. L. Gobby, A. A. Hauer, K. A. Klare, J. A. Oertel, R. G. Watt, D. C. Wilson, W. S. Varnum, R. S. Craxton, V. Yu. Glebov, J. D. Schnittman, C. Stoeckl, S. M. Pollaine, and R. E. Turner, Phys. Plasmas 7, 2594 (2000).

[75] D. Callahan-Miller and M. Tabak, Phys. Plasmas 7, 2083 (2000).

[76] M. E. Cuneo, R. A. Vesey, J. H. Hammer, and J. L. Porter, Jr., to be published in Lasers Particle Beams.

[77] R. Olson, G. Chandler, and R. Leeper, Bull. Am. Phys. Soc. 45, No. 7, 298 (2000).

[78] T. W. L. Sanford, R. E. Olson, R. A. Vesey, G. A. Chandler, D. E. Hebron, R. C. Mock, R. J. Leeper, T. J. Nash, C. L. Ruiz, L. E. Ruggles, W. W. Simpson, R. L. Bowers, W. Matuska, D. L. Peterson, and R. R. Peterson, Fusion Tech. 38, 11 (2000).

[79] T. W. L. Sanford, R. E. Olson, R. C. Mock, G. A. Chandler, R. J. Leeper, T. J. Nash, L. E. Ruggles, W. W. Simpson, K. W. Struve, D. L. Peterson, R. L. Bowers, and W. Matuska, to be published in Phys. Plasmas 7 (2000).

[80] L. Suter, J. Rothenberg, D. Munro, B. Van Wonterghem, and S. Haan, Phys. Plasmas 7, 2092 (2000).

[81] M. E. Cuneo, R. A. Vesey, J. L. Porter, Jr., G. A. Chandler, D. L. Fehl, T. L. Gilliland, D. L. Hanson, J. S. McGurn, P. G. Reynolds, L. E. Ruggles, J. J. Seamen, R. B. Spielman, K. W. Struve, W. A. Stygar, W. W. Simpson, J. A. Torres, D. F. 
Wenger, J. H. Hammer, P. W. Rambo, D. L. Peterson, and G. C. Idzorek., to be published in Phys. Plasmas.

[82] S. A. Slutz, M. R. Douglas, J. S. Lash, R. A. Vesey, G. A. Chandler, T. J. Nash, and M. S. Derzon, submitted to Phys. Plasmas.

[83] R. E. Olson, T. W. L. Sanford, G. A. Chandler, R. J. Leeper, R. C. Mock, J. S. McGurn, S. E. Lazier, J. C. Armijo, S. Dropinski, R. E. Ruggles, W. W. Simpson, J. A. Torres, and C. Wakefield, to be published in Rev. Sci. Instrum. 72 (January 2001). [84] R. E. Marshak, Phys. Fluids 1, 24 (1958).

[85] R. Pakula and R. Sigel, Phys. Fluids 28, 232 (1985); 29, 1340(E) (1986).

[86] F. Reif, Fundamentals of statistical and thermal physics (McGraw-Hill Book Company, New York, 1965) p. 387.

[87] J. F. Cuderman and K. M. Gilbert, Rev. Sci. Instrum. 46, 53 (1975).

[88] H. N. Kornblum, R. L. Kaufmann, and J. A. Smith, Rev. Sci. Instrum., 57, 2179 (1986).

[89] D. R. Kania, L. S. Pan, P. Bell, O. L. Landen, H. Kornblum, P. Pianetta, and M. D. Perry, J. Appl. Phys. 68, 124 (1990).

[90] D. R. Kania, L. Pan, H. Kornblum, P. Bell, O. N. Landen, and P. Pianetta, Rev. Sci. Instrum. 61, 2765 (1990).

[91] L. S. Pan, D. R. Kania, P. Pianetta, and O. L. Landen, Appl. Phys. Lett. 57, 623 (1990).

[92] R. B. Spielman, Rev. Sci. Instrum. 63, 5056 (1992).

[93] F. Ze, R. L. Kauffman, J. D. Kilkenny, J. Wielwald, P. M. Bell, R. Hanks, J. Stewart, D. Dean, J. Bower, R. Wallace, Rev. Sci. Instrum. 63, 5124 (1992).

[94] A. Hauer, N. Delamater, D. Ress, W. Hsing, L. Suter, L. Powers, O. Landen, D. Harris, R. Thiessen, G. Magelssen, E. Lindman, D. Phillion, P. Amendt, R. Watt, and B. Hammel, Rev. Sci. Instrum. 66, 672 (1995).

[95] R. L. Kauffman, H. N. Kornblum, D. W. Phillion, C. B. Darrrow, B. F. Lasinski, L. J. Suter, A. R. Theissen, R. J. Wallace, and F. Ze, Rev. Sci. Instrum. 66, 678 (1995).

[96] R. B. Spielman, Rev. Sci. Instrum. 66, 867 (1995).

[97] D. L. Fehl and F. Biggs, Rev. Sci. Instrum. 68, 890 (1997).

[98] D. L. Fehl, G. A. Chandler, F. Biggs, R. J. Dukart, A. R. Moats, and R. J. Leeper, Rev. Sci. Instrum. 68, 843 (1997).

[99] S. Han, Rev. Sci. Instrum. 68, 647 (1997).

[100] G. C. Idzorek and R. J. Bartlett, Proc. SPIE 3114, 349 (1997).

[101] R. B. Spielman, L. E. Ruggles, R. E. Pepping, S. P. Breeze, J. S. McGurn, and K. W. Struve, Rev. Sci. Instrum. 68, 782 (1997). 
[102] K. L. Baker, J. L. Porter, L. E. Ruggles, D. L. Fehl, G. A. Chandler, M. Vargas, L. P. Mix, W. W. Simpson, C. Deeney, R. E. Chrien, and G. C. Idzorek, Rev. Sci. Instrum. 70, 2012 (1999).

[103] G. A. Chandler, C. Deeney, M. Cuneo, D. L. Fehl, J. S. McGurn, R. B. Spielman, J. A. Torres, J. L. McKenney, J. Mills, and K. W. Struve, Rev. Sci. Instrum. 70, 561 (1999).

[104] R. B. Spielman, C. Deeney, D. L. Fehl, D. L. Hanson, N. R. Keltner, J. S. McGurn, and J. L. McKenney, Rev. Sci. Instrum. 70, 651 (1999).

[105] R. E. Turner, O. L. Landen, P. Bell, R. Costa, and D. Hargrove, Rev. Sci. Instrum. 70, 656 (1999).

[106] D. L. Fehl, F. Biggs, G. A. Chandler, and W. A. Stygar, Rev. Sci. Instrum. 71, 3072 (2000).

[107] R. Byron Bird, Warren E. Stewart, and Edwin N. Lightfoot, Transport Phenomena (John Wiley and Sons, Inc., New York, 1960), pp. 437-443.

[108] Ya. B. Zel'dovich and Yu. P. Raizer, Physics of Shock Waves and High-

Temperature Hydrodynamic Phenomena (Academic Press, New York, 1966), Vol. I, pp. $192-215$.

[109] Y. T. Lee, J. Quant. Spectrosc. Radiat. Transfer 38, 131 (1987).

[110] CRC Handbook of Chemistry and Physics $-81^{\text {st }}$ Edition, edited by David R. Lide (CRC Press, New York, 2000), pp. 10-175 to 10-177.

[111] M. E. Cuneo (private communication). 